\title{
Effects of irrigation treatments on the quality of table olives produced with the Greek-style process
}

\author{
Alessandra Martorana ${ }^{1,2}$ - Claudia Di Miceli ${ }^{1}$ - Antonio Alfonzo ${ }^{1} \cdot$ Luca Settanni $^{1}$. \\ Raimondo Gaglio $^{1} \cdot$ Tiziano Caruso $^{1} \cdot$ Giancarlo Moschetti $^{1} \cdot$ Nicola Francesca $^{1}$
}

Received: 19 May 2016 / Accepted: 6 September 2016

(C) Springer-Verlag Berlin Heidelberg and the University of Milan 2016
Keywords Lactic acid bacteria $\cdot$ Yeasts $\cdot$ Nocellara del Belice table olive $\cdot$ Regulated deficit irrigation $\cdot$ Carpological characteristic $\cdot$ Water

\section{Introduction}

Traditionally, olive trees are not watered (Caruso and Di Marco 1982), but due to the growing interest of table olive producers, the majority of olive groves are going to be replaced by intensive cultivation systems (Vossen 2007), subjected to periodic irrigation. The irrigation of table olive trees has several positive effects: it improves vegetative and reproductive growth, increases the size and uniformity of drupes, and reduces fruit drop and alternate bearing (Lavee et al. 1990; Michelakis 1990; Patumi et al. 2002).

Generally, the irrigation scheduling is established following the indications of the Food and Agriculture Organization of the United Nations (FAO), applying the estimated evapotranspiration (100\% ETc) based on the fully replenishing soil water extraction (Allen et al. 1998). Proietti and Antognozzi (1996) studied the effect of irrigation on the vegetative and productive activities of trees, as well as on the quality of table olives belonging to the cultivar Ascolana. Those authors registered a significant increase of weight, volume, and flesh:pit ratio. Recently, other authors (Patumi et al. 2002; Tovar et al. 2002; Marsilio et al. 2006; García et al. 2014) reported that drupes from irrigated olive trees are characterized by lower contents in phenolic compounds than those from not irrigated trees, evidencing an effect of the irrigation on the chemical composition of the drupes. However, the effects of different regulated deficit irrigation (RDI) strategies applied to olive orchards have been evaluated, so far, on the drupes for oil extraction rather than table olive production (Goldhamer 1999; Iniesta et al. 2009). Following this trend, a large number 
of scientific papers have been published on the quality of olive oils produced from drupes obtained from trees subjected to irrigation (Pastor et al. 1998; Gómez-Rico et al. 2006, 2007; Servili et al. 2007), but no information on fermented table olives is available.

Although Marsilio et al. (2006) monitored some aspects of table olives produced from drupes grown under RDI and produced in accordance to Greek-style, no data have been provided on the microbiological quality during fermentation in terms of concentration of spoilage and potential pathogenic microorganisms, as well as diversity of pro-technological microorganisms, in particular lactic acid bacteria (LAB), but also yeasts. Aponte et al. (2012) monitored the microbial populations of two Spanish-like fermentations of green table olives of the cultivar "Nocellara del Belice", coming from irrigated and not irrigated fields in order to isolate LAB strains with relevant technological properties, but registered that yeast and staphylococcal populations were higher in the production carried out with olives harvested from not irrigated fields.

In recent years, the use of selected LAB strains (Aponte et al. 2012; Martorana et al. 2016) and innovative methods to ferment table olives (Martorana et al. 2015) is growing, but the spontaneous fermentation method is still widely applied to produce olives at the industrial level. The spontaneous fermentation takes place thanks to the indigenous olive surface microflora consisting mainly of Gram-negative bacteria (Enterobacteriaceae), LAB, and yeasts. Several spoilage microorganisms belonging to the genera Pseudomonas and Staphylococcus (Heperkan 2013) could also be encountered during the olive manufacturing process. When the $\mathrm{pH}$ decreases to 5.0, consistent levels of LAB are commonly found. LAB coexist with yeasts that become dominant in the last stage of fermentation and influence the sensory characteristics of the final product (Garrido et al. 1995; Garrido Fernández et al. 1997; Arroyo-López et al. 2008). However, an overgrowth of fermentative yeasts could produce a vigorous production of $\mathrm{CO}_{2}$ that could damage drupe texture (FernándezDíez et al. 1985).

The aim of this work was to register the effects of different irrigation treatments on the carpological, physico-chemical, microbiological, and sensory characteristics of Greek-style table olives. The work was carried out using the cv. Nocellara del Belice, due to its importance in Sicily.

\section{Materials and methods}

\section{Plant material, growing conditions, and experimental design}

The experimental production of table olives was performed with drupes of "Nocellara del Belice" cultivar. The study was carried out during two consecutive olive crop seasons (20132014) in a 13-ha section of a commercial olive orchard located in Castelvetrano $\left(37^{\circ} 41^{\prime} 0^{\prime \prime} \mathrm{N} \mathrm{12} 2^{\circ} 47^{\prime} 35^{\prime \prime} \mathrm{E}\right.$; Trapani, Sicily, Italy). Adult trees (about 60 years old) spaced $5 \times 7 \mathrm{~m}$ were included in the experimental design.

The experimental plan included the following three trials: two RDI treatments were managed in order to supply, respectively, $100 \%$ (trial T100) and $50 \%$ (trial T50) of the ETc.; the trial T0 did not receive water. From July to September, trees managed with trials T100 and T50 received $1500 \mathrm{~m}^{3} / \mathrm{ha}$ and $750 \mathrm{~m}^{3} /$ ha of water, respectively. Irrigation was performed weekly, starting soon after the pit hardening (July) occurred and ending in autumn, when the rain season started.

In accordance to FAO methodology (Allen et al. 1998), $100 \%$ ETc was based on the fully replenishing soil water extraction. The ETc was calculated applying the method proposed by Doorenbos and Pruitt (1977): ETc $=\mathrm{ETo} \times \mathrm{Kc} \times \mathrm{Kr}$, where a crop coefficient $(\mathrm{Kc})$, representing the ratio of crop evapotranspiration $(\mathrm{ETc})$ to reference evapotranspiration (ETo), is adjusted by the crop cover $(\mathrm{Kr})$ (Fereres and Castel 1981). Kc suggested for olive trees growing under the conditions reigning in Castelvetrano (from 0.66 to 0.77 ) was estimated considering 30 years of climatic data (Servizio Informativo Agrometeorologico Siciliano, SIAS). Irrigation was supplied with a sub-irrigation pipe system. Two lateral pipes wings (0.50 m depth) which support micro-emitters $(4 \mathrm{~L} / \mathrm{h})$, spacing each other along the pipes, were installed per tree row.

A randomized complete-block design was used with three blocks per treatment and two trees per block. Irrigation scheduling was controlled with the measurements of six trees per treatment (two per block) during the growing season.

\section{Table olive processing and sample collection}

Olive drupes were manually harvested at the suitable maturity stage for table olive processing and immediately transported to the manufacturer located in Castelvetrano (Italy), where they were mixed separately for each trial. Amounts of $150 \mathrm{~kg}$ of drupes for each trial were transferred into vats of $180 \mathrm{~L}$ volume, filled with $30 \mathrm{~L}$ of brine composed of $\mathrm{NaCl}$ $9 \%(\mathrm{w} / \mathrm{v})$, and subjected to spontaneous fermentation. The brine salt concentration was constantly maintained at the initial level by periodical addition of coarse salt. The fermentation of all trials was carried out at room temperature for 220 days and was monitored periodically. Samples of brine (about $50 \mathrm{~mL}$ ) were collected at 4, 11, 24, 41, 80, 120, 160, and 220 days of fermentation. The experiment was performed in triplicate (three vats per trial) in two consecutive olive crop seasons (2013 and 2014).

\section{Carpological measurement, pH monitoring, and microbiological analyses}

Olive drupes from single trees were selected in commercial calibers (diameter bigger than $19 \mathrm{~mm}$ ). For quality 
assessment, about $2.5 \mathrm{~kg}$ of table olives (corresponding to about 500 drupes) per treatment was randomly selected and the weight of flesh and stone was measured using a digital scale (ORMA mod. BC, Italy). The equatorial diameter (ED) of the olives was measured using a digital caliper (SAMA Tools, Italy).

The $\mathrm{pH}$ of brines was measured using the $\mathrm{pH}$ meter BASIC $20+$ (Crison Instrument S.A., Barcelona, Spain), calibrated with three standard solutions at $\mathrm{pH} 4.0,7.0$, and 9.2.

The cell densities of LAB, yeasts, Enterobacteriaceae, pseudomonads, staphylococci, and coagulase-positive staphylococci (CPS) were determined as reported by Martorana et al. (2015) after decimal dilutions of brines prepared in Ringer's solution (Sigma-Aldrich, Milan, Italy).

\section{Isolation, grouping, and genotypic differentiation of LAB}

At least four colonies with identical aspect were collected from the highest dilutions of cell suspension inoculated on Man-Rogosa-Sharpe (MRS) agar for all the morphologies of the presumptive LAB. The isolates were purified by successive sub-culturing on the same medium and the purity was checked microscopically to ascertain a unique cell morphology per culture. Grampositive (determined by the Gregersen $\mathrm{KOH}$ method) and catalase-negative (determined in the presence of $\mathrm{H}_{2} \mathrm{O}_{2} 5 \%, \mathrm{v} / \mathrm{v}$ ) were stored in broth containing $20 \%$ (v/v) glycerol at $-80{ }^{\circ} \mathrm{C}$ until further experimentations. LAB were initially subjected to a phenotypic grouping based on cell morphology and disposition, growth at 15 and $45{ }^{\circ} \mathrm{C}$, and metabolism type, testing the ability to produce $\mathrm{CO}_{2}$ from glucose. The last assay was carried out with the same growth media used for isolation without citrate from which certain LAB produce gas. The obligate homofermentative metabolism was determined by the absence of growth in the presence of a mixture of pentose carbohydrates (xylose, arabinose, and ribose; $8 \mathrm{~g} / \mathrm{L}$ each) in place of glucose. Sub-grouping of cocci included also the growth at $\mathrm{pH} 9.6$ and in the presence of $6.5 \%(\mathrm{w} / \mathrm{v}) \mathrm{NaCl}$.

DNA from LAB isolates was extracted using the InstaGene Matrix kit (Bio-Rad Laboratories, Hercules, CA), according to the manufacturer's instructions. Presumptive LAB were grouped by random amplification of polymorphic DNA polymerase chain reaction (RAPD-PCR) analysis in a $25-\mu \mathrm{L}$ reaction mix using a single primer M13 as previously described by Gaglio et al. (2014). The identification at the species level was performed by multiplex PCR analysis of the recA gene with species-specific primers for Lactobacillus pentosus, Lactobacillus plantarum, and Lactobacillus paraplantarum, according to the protocol described by Torriani et al. (2001). One representative culture for each multiplex cluster and all strains that did not show amplification by multiplex PCR analysis were analyzed by $16 \mathrm{~S}$ rRNA gene sequencing, as described by Weisburg et al. (1991). DNA sequencing reactions were performed at Eurofins Genomics S.r.l. (Milan, Italy). The identities of the sequences were determined by BlastN search against the NCBI non-redundant sequence database located at http://www.ncbi.nlm.nih.gov and those available at EzTaxon located at http://www.ezbiocloud. net/eztaxon.

\section{Isolation and genotypic characterization of yeasts}

At least five colonies per morphology on agar plates were randomly collected from dichloran rose bengal chloramphenicol (DRBC) medium, and after purification onto the same medium of isolation, the cultures were identified genotypically.

DNA extraction was performed as reported above. All isolates were preliminary grouped by restriction fragment length polymorphism (RFLP) analysis of the region
Table 1 Carpological characteristics of olive drupes

\begin{tabular}{lllll}
\hline Treatment & $\begin{array}{l}\text { Fruit equatorial } \\
\text { diameter }(\mathrm{mm})\end{array}$ & Fruit weight $(\mathrm{g})$ & Pit weight $(\mathrm{g})$ & Flesh:pit ratio \\
\hline T100 & $21.97 \pm 0.18^{\mathrm{b}}$ & $6.85 \pm 0.06^{\mathrm{b}}$ & $0.93 \pm 0.05^{\mathrm{a}}$ & $6.49 \pm 0.14^{\mathrm{c}}$ \\
T50 & $21.39 \pm 0.16^{\mathrm{b}}$ & $6.48 \pm 0.11^{\mathrm{b}}$ & $1.03 \pm 0.03^{\mathrm{a}}$ & $5.73 \pm 0.19^{\mathrm{b}}$ \\
T0 & $20.25 \pm 0.11^{\mathrm{a}}$ & $5.54 \pm 0.07^{\mathrm{a}}$ & $0.94 \pm 0.04^{\mathrm{a}}$ & $4.87 \pm 0.09^{\mathrm{a}}$ \\
Statistical significance & $*$ & $*$ & N.S. & $*$ \\
\hline
\end{tabular}

The results indicate mean values \pm standard error of three measurements (carried out in triplicate for two olive crop seasons)

T100 irrigated trial performed with $100 \%$ of the ETc, T50 irrigated trial performed with $50 \%$ of the ETc, T0 rainfed trial

${ }^{\S}$ Data within a column followed by the same letter are not significantly different according to Tukey’s test. $p$ value: $p \leq 0.05$; N.S., not significant; *significant 
spanning the internal transcribed spacers (ITS1 and ITS2) and the 5.8S rRNA gene, as reported by EsteveZarzoso et al. (1999). One isolate per group was identified at the species level by sequencing the D1/D2 region of the $26 \mathrm{~S}$ rRNA gene to confirm the preliminary identification obtained by RFLP analysis. The D1/D2

Table 2 Values of $\mathrm{pH}$ and microbial concentrations of brine samples

\begin{tabular}{|c|c|c|c|c|c|c|c|c|c|}
\hline & \multicolumn{9}{|c|}{ Days of fermentation } \\
\hline & 0 & 4 & 11 & 24 & 41 & 80 & 120 & 160 & 220 \\
\hline \multicolumn{10}{|l|}{$\mathrm{pH}$} \\
\hline $\mathrm{T} 100$ & $7.0 \pm 0.1^{\mathrm{a}}$ & $6.6 \pm 0.1^{\mathrm{a}, \mathrm{b}}$ & $5.0 \pm 0.1^{\mathrm{b}}$ & $4.2 \pm 0.0^{\mathrm{b}}$ & $4.0 \pm 0.1^{\mathrm{b}}$ & $3.9 \pm 0.1^{\mathrm{b}}$ & $3.9 \pm 0.0^{\mathrm{b}}$ & $3.9 \pm 0.0^{\mathrm{a}}$ & $3.8 \pm 0.0^{\mathrm{a}}$ \\
\hline $\mathrm{T} 50$ & $7.0 \pm 0.1^{\mathrm{a}}$ & $6.6 \pm 0.1^{\mathrm{b}}$ & $4.9 \pm 0.1^{\mathrm{b}}$ & $4.3 \pm 0.1^{\mathrm{b}}$ & $4.1 \pm 0.1^{\mathrm{b}}$ & $3.9 \pm 0.0^{\mathrm{b}}$ & $3.9 \pm 0.1^{\mathrm{a}}$ & $3.9 \pm 0.1^{\mathrm{a}}$ & $3.9 \pm 0.1^{\mathrm{a}}$ \\
\hline T0 & $7.2 \pm 0.0^{\mathrm{a}}$ & $6.9 \pm 0.1^{\mathrm{a}}$ & $5.7 \pm 0.0^{\mathrm{a}}$ & $4.9 \pm 0.1^{\mathrm{a}}$ & $4.5 \pm 0.1^{\mathrm{a}}$ & $4.3 \pm 0.0^{\mathrm{a}}$ & $4.3 \pm 0.0^{\mathrm{a}}$ & $4.1 \pm 0.1^{\mathrm{a}}$ & $3.9 \pm 0.1^{\mathrm{a}}$ \\
\hline Statistical significance ${ }^{\S}$ & N.S. & $*$ & $*$ & $*$ & $*$. & $*$ & $*$ & N.S. & N.S. \\
\hline \multicolumn{10}{|l|}{ MRS } \\
\hline $\mathrm{T} 100$ & $1.7 \pm 0.1^{\mathrm{a}}$ & $2.2 \pm 0.4^{\mathrm{a}}$ & $2.1 \pm 0.5^{\mathrm{a}}$ & $1.9 \pm 0.1^{\mathrm{a}}$ & $1.7 \pm 0.1^{\mathrm{a}}$ & $1.0 \pm 0.6^{\mathrm{a}}$ & $1.4 \pm 0.4^{\mathrm{a}}$ & $3.5 \pm 0.5^{\mathrm{a}}$ & $4.6 \pm 0.2^{\mathrm{b}}$ \\
\hline $\mathrm{T} 50$ & $1.1 \pm 0.1^{\mathrm{b}}$ & $1.0 \pm 0.1^{\mathrm{b}}$ & $2.0 \pm 0.1^{\mathrm{a}}$ & $1.1 \pm 0.2^{\mathrm{b}}$ & $1.1 \pm 0.1^{\mathrm{b}}$ & $1.2 \pm 0.4^{\mathrm{a}}$ & $1.1 \pm 0.5^{\mathrm{a}}$ & $3.3 \pm 0.4^{\mathrm{a}}$ & $6.0 \pm 0.2^{\mathrm{a}, \mathrm{b}}$ \\
\hline $\mathrm{T} 0$ & $1.7 \pm 0.2^{\mathrm{a}}$ & $1.0 \pm 0.2^{\mathrm{b}}$ & $1.1 \pm 0.2^{\mathrm{b}}$ & $1.0 \pm 0.1^{\mathrm{b}}$ & $1.0 \pm 0.2^{\mathrm{b}}$ & $1.0 \pm 0.2^{\mathrm{a}}$ & $1.2 \pm 0.2^{\mathrm{a}}$ & $1.5 \pm 0.1^{\mathrm{b}}$ & $6.2 \pm 0.1^{\mathrm{a}}$ \\
\hline Statistical significance ${ }^{\S}$ & $*$ & $*$ & $*$ & $*$ & $*$ & N.S. & N.S. & $*$ & $*$ \\
\hline \multicolumn{10}{|l|}{ DRBC } \\
\hline $\mathrm{T} 100$ & $3.7 \pm 0.1^{\mathrm{a}}$ & $5.0 \pm 0.1^{\mathrm{a}}$ & $3.9 \pm 0.4^{\mathrm{a}, \mathrm{b}}$ & $2.6 \pm 0.1^{\mathrm{a}}$ & $1.6 \pm 0.1^{\mathrm{a}}$ & $1.2 \pm 0.1^{\mathrm{b}}$ & $1.2 \pm 0.7^{\mathrm{a}}$ & $5.0 \pm 0.4^{\mathrm{a}}$ & $6.1 \pm 0.4^{\mathrm{a}}$ \\
\hline $\mathrm{T} 50$ & $3.8 \pm 0.3^{\mathrm{a}}$ & $5.4 \pm 0.3^{\mathrm{a}}$ & $3.5 \pm 0.3^{\mathrm{b}}$ & $2.6 \pm 0.3^{\mathrm{a}}$ & $2.2 \pm 0.1^{\mathrm{a}}$ & $2.1 \pm 0.2^{\mathrm{a}}$ & $2.4 \pm 0.4^{\mathrm{a}}$ & $5.5 \pm 0.5^{\mathrm{a}}$ & $6.2 \pm 0.2^{\mathrm{a}}$ \\
\hline $\mathrm{T} 0$ & $3.9 \pm 0.7^{\mathrm{a}}$ & $5.1 \pm 0.6^{\mathrm{a}}$ & $5.3 \pm 0.4^{\mathrm{a}}$ & $2.5 \pm 0.7^{\mathrm{a}}$ & $1.3 \pm 0.7^{\mathrm{a}}$ & $1.0 \pm 0.2^{\mathrm{b}}$ & $1.6 \pm 0.3^{\mathrm{a}}$ & $5.5 \pm 0.7^{\mathrm{a}}$ & $6.0 \pm 0.1^{\mathrm{a}}$ \\
\hline Statistical significance ${ }^{\S}$ & N.S. & N.S. & $*$ & N.S. & N.S. & $*$ & N.S. & N.S. & N.S. \\
\hline \multicolumn{10}{|l|}{ VRBGA } \\
\hline $\mathrm{T} 100$ & $1.0 \pm 0.2^{\mathrm{a}}$ & $2.7 \pm 0.6^{\mathrm{a}, \mathrm{b}}$ & $2.4 \pm 0.4^{\mathrm{a}}$ & $1.2 \pm 0.4^{\mathrm{a}}$ & n.d. & n.d. & n.d. & n.d. & n.d. \\
\hline $\mathrm{T} 50$ & $1.2 \pm 0.2^{\mathrm{a}}$ & $2.3 \pm 0.3^{b}$ & $2.3 \pm 0.3^{\mathrm{a}}$ & $1.5 \pm 0.1^{\mathrm{a}}$ & n.d. & n.d. & n.d. & n.d. & n.d. \\
\hline $\mathrm{T} 0$ & $1.3 \pm 0.3^{\mathrm{a}}$ & $3.9 \pm 0.2^{\mathrm{a}}$ & $3.6 \pm 0.8^{\mathrm{a}}$ & $2.0 \pm 0.3^{\mathrm{a}}$ & n.d. & n.d. & n.d. & n.d. & n.d. \\
\hline Statistical significance ${ }^{\S}$ & N.S. & $*$ & N.S. & N.S. & & & & & \\
\hline \multicolumn{10}{|l|}{ PAB } \\
\hline $\mathrm{T} 100$ & n.d. & $1.3 \pm 0.1^{\mathrm{a}}$ & $3.7 \pm 0.4^{\mathrm{a}}$ & $3.9 \pm 0.8^{\mathrm{a}}$ & $4.6 \pm 0.1^{\mathrm{a}}$ & $1.9 \pm 0.4^{\mathrm{b}}$ & n.d. & n.d. & n.d. \\
\hline $\mathrm{T} 50$ & n.d. & $1.7 \pm 0.2^{\mathrm{a}}$ & $3.9 \pm 0.7^{\mathrm{a}}$ & $4.0 \pm 0.3^{\mathrm{a}}$ & $4.8 \pm 0.5^{\mathrm{a}}$ & $2.8 \pm 0.6^{\mathrm{a}, \mathrm{b}}$ & n.d. & n.d. & n.d. \\
\hline T0 & n.d. & $2.1 \pm 0.7^{\mathrm{a}}$ & $5.0 \pm 0.2^{\mathrm{a}}$ & $4.3 \pm 0.1^{\mathrm{a}}$ & $5.5 \pm 0.8^{\mathrm{a}}$ & $3.9 \pm 0.1^{\mathrm{a}}$ & $1.3 \pm 0.1$ & $1.1 \pm 0.0$ & n.d. \\
\hline Statistical significance ${ }^{\S}$ & & N.S. & N.S. & N.S. & N.S. & $*$ & $*$ & $*$ & \\
\hline \multicolumn{10}{|l|}{ BP } \\
\hline $\mathrm{T} 100$ & n.d. & $1.5 \pm 0.3^{\mathrm{a}}$ & $3.9 \pm 0.4^{\mathrm{a}}$ & $4.2 \pm 0.2^{\mathrm{a}}$ & $4.8 \pm 0.4^{\mathrm{a}}$ & $2.2 \pm 0.1^{\mathrm{c}}$ & n.d. & n.d. & n.d. \\
\hline $\mathrm{T} 50$ & n.d. & $1.3 \pm 0.3^{\mathrm{a}}$ & $3.7 \pm 0.4^{\mathrm{a}}$ & $4.1 \pm 0.5^{\mathrm{a}}$ & $4.9 \pm 0.6^{\mathrm{a}}$ & $3.1 \pm 0.2^{\mathrm{b}}$ & n.d. & n.d. & n.d. \\
\hline T0 & n.d. & $1.9 \pm 0.1^{\mathrm{a}}$ & $4.2 \pm 0.6^{\mathrm{a}}$ & $4.8 \pm 0.4^{\mathrm{a}}$ & $5.4 \pm 0.4^{\mathrm{a}}$ & $4.5 \pm 0.4^{\mathrm{a}}$ & $2.1 \pm 0.4$ & $1.1 \pm 0.7$ & n.d. \\
\hline Statistical significance ${ }^{\S}$ & & N.S. & N.S. & N.S. & N.S. & $*$ & $*$ & $*$ & \\
\hline \multicolumn{10}{|l|}{ PCA } \\
\hline $\mathrm{T} 100$ & $4.3 \pm 0.7^{\mathrm{a}}$ & $5.3 \pm 0.2^{\mathrm{a}}$ & $5.2 \pm 0.2^{\mathrm{a}}$ & $3.1 \pm 0.2^{\mathrm{a}}$ & $2.4 \pm 0.3^{\mathrm{a}}$ & $2.1 \pm 0.1^{\mathrm{a}}$ & $2.1 \pm 0.2^{\mathrm{a}}$ & $4.5 \pm 0.1^{\mathrm{a}}$ & $6.2 \pm 0.7^{\mathrm{a}}$ \\
\hline $\mathrm{T} 50$ & $3.8 \pm 0.4^{\mathrm{a}}$ & $5.6 \pm 0.2^{\mathrm{a}}$ & $4.0 \pm 0.5^{\mathrm{a}}$ & $2.9 \pm 0.3^{\mathrm{a}}$ & $1.2 \pm 0.6^{\mathrm{a}}$ & $0.9 \pm 0.1^{\mathrm{b}}$ & $1.0 \pm 0.4^{\mathrm{b}}$ & $5.6 \pm 0.9^{\mathrm{a}}$ & $6.3 \pm 0.5^{\mathrm{a}}$ \\
\hline $\mathrm{T} 0$ & $3.5 \pm 0.2^{\mathrm{a}}$ & $5.2 \pm 0.4^{\mathrm{a}}$ & $4.9 \pm 0.5^{\mathrm{a}}$ & $2.2 \pm 0.2^{\mathrm{b}}$ & $1.6 \pm 0.4^{\mathrm{a}}$ & $1.4 \pm 0.3^{\mathrm{b}}$ & $2.0 \pm 0.2^{\mathrm{a}}$ & $5.6 \pm 0.5^{\mathrm{a}}$ & $6.1 \pm 0.1^{\mathrm{a}}$ \\
\hline Statistical significance ${ }^{\S}$ & N.S. & N.S. & N.S. & $*$ & N.S. & $*$ & $*$ & N.S. & N.S. \\
\hline
\end{tabular}

The results of microbial loads are expressed as Log colony-forming units (CFU)/mL and indicate the mean values \pm standard deviation of three plate counts (carried out in triplicate for two olive crop seasons)

T100 irrigation supplied $100 \%$ of the ETc, T50 irrigation supplied $50 \%$ of the ETc, T0 rainfed trial, MRS Man-Rogosa-Sharpe agar for mesophilic rod LAB, DRBC dichloran rose bengal chloramphenicol agar for total yeasts and filamentous fungi, VRBGA violet red bile glucose agar for Enterobacteriaceae, PAB Pseudomonas agar base for pseudomonads, BP Baird-Parker agar base for staphylococci, n.d. not detected (value $<$ detection limit of method)

${ }^{\S}$ Data within a column followed by the same letter are not significantly different according to Tukey’s test. $p$-value: $p \leq 0.05$; N.S., not significant; *significant 
region was amplified and the PCR products were visualized as described by Francesca et al. (2014). The reaction of DNA sequencing and the identities of the sequences were determined as reported above.

\section{Sensory evaluation}

Evaluation of the sensory profiles of the experimental olives was performed using a descriptive method (UNI 10957 2003), as reported by Martorana et al. (2016). A total of 16 descriptors were included in the analysis for the external aspect (green color intensity and brightness), odor (green olive aroma, complexity, and off-odours), taste (crispness, easy stone that means easy pit detachment from the flesh, juicy, sweet, sour, bitter, salt, astringent, and complexity), flavours and overall satisfaction. The olive samples were randomly evaluated by assigning a score between 1.00 (absence of sensation) and 9.00 (extremely intense) in individual booths under incandescent white light.

Sensory tests were performed with three evaluations for each trial. Each evaluation was carried out in different test sessions at the same time of day. Assessors conducted no more than three tests per day, lasting a maximum of $1 \mathrm{~h}$.

\section{Statistical and explorative multivariate analysis}

Data from carpological, physico-chemical, microbiological, and sensory analyses were investigated using a generalized linear model (GLM) based on the analysis of variance (ANOVA) model that included effects of olive crop seasons (2013 and 2014 years) and irrigation (100\%, 50\%, and $0 \%$ of the ETc.), as well as the interaction between olive crop seasons and irrigation strategies. The post-hoc Tukey's method was applied for pairwise comparison. Statistical significance was attributed to $p$-values of $<0.05$.

In order to represent graphically the values of the microbial counts, a heat map clustered analysis (HMCA), based on double hierarchical dendrogram with heat map plot, was employed to represent the individual content values contained in the data matrix as colors. The values of counts for microbial groups were depicted by color intensity from yellow (lowest concentration) to red (highest concentration). Heat map analysis of the volatile levels was performed using the autoscaled data. Graphical construction was achieved by using XLSTAT software version 7.5.2 (Addinsoft, New York, USA) for Excel.

In addition, an explorative multivariate analysis was employed to investigate the relationships among data obtained from the different measurements. Principal component analysis (PCAn) was employed to investigate the relationships among samples. The input matrix used for PCAn consisted of the total area under the growth/decline curves of total mesophilic count, LAB, yeasts, enterobacteria, pseudomonads, CPS, as well as $\mathrm{pH}$ values (Bautista-Gallego et al. 2011; Blana et al. 2014). Areas were calculated by integration using the OriginPro 7.5 software (OriginLab Corporation, Northampton, MA, USA). In addition, other relevant indexes of $\mathrm{pH}$ and microbial changes were taken into account as follows: maximum and minimum values of $\mathrm{pH}$, maximum and minimum values of microbial populations (Bautista-Gallego et al. 2011). The number of principal factors was selected according to the Kaiser criterion (Jolliffe 1986) and only factors with eigenvalues higher than 1.00 were retained. All data were preliminary evaluated by using Bartlett's sphericity test (Dillon and Goldstein 1984; Mazzei et al. 2010) in order to check the statistically significant difference among samples within each dataset. Statistical

Table 3 Molecular identification of lactic acid bacteria (LAB) species during the table olive production

\begin{tabular}{|c|c|c|c|c|c|c|c|c|}
\hline \multirow[t]{2}{*}{ Species } & \multirow[t]{2}{*}{ Strain } & \multirow{2}{*}{$\begin{array}{l}\text { Isolation source } \\
\text { (day of sampling) }\end{array}$} & \multirow{2}{*}{$\begin{array}{l}\text { Size of } \\
\text { multiplex } \\
\text { PCR }^{\mathrm{a}} \\
\text { amplicon }\end{array}$} & \multicolumn{2}{|c|}{$\%$ similarity $^{\mathrm{b}}$ (accession no. of closest relative) by: } & \multirow{2}{*}{$\begin{array}{l}\text { Sequence } \\
\text { length (bp) }\end{array}$} & \multirow{2}{*}{$\begin{array}{l}\text { Accession } \\
\text { no. }\end{array}$} & \multirow{2}{*}{$\begin{array}{l}\text { No. of isolates } \\
\text { (\% relative } \\
\text { abundance) }\end{array}$} \\
\hline & & & & BLAST & EzTaxon & & & \\
\hline $\begin{array}{l}\text { Lactobacillus } \\
\text { coryniformis }\end{array}$ & AMol-2 & $\mathrm{T} 100(120)$ & n.a. & 99 (KF994925.1) & $98.72\left(\mathrm{KCTC} 3535^{\mathrm{T}}\right)$ & 1484 & KU240501 & $123(8.9)$ \\
\hline $\begin{array}{l}\text { Lactobacillus } \\
\text { pentosus }\end{array}$ & AMol-1 & $\mathrm{T} 50(11)$ & 218 & $99($ KT215616.1) & $99.86\left(\mathrm{JCM} 1558^{\mathrm{T}}\right)$ & 1476 & KU240502 & $677(48.9)$ \\
\hline $\begin{array}{c}\text { Lactobacillus } \\
\text { plantarum }\end{array}$ & AMol-4 & $\mathrm{T} 100(4)$ & 318 & $100($ KT268296.1) & $99.80\left(\mathrm{ATCC} 14917^{\mathrm{T}}\right)$ & 1488 & KU240503 & $387(27.9)$ \\
\hline $\begin{array}{l}\text { Pediococcus } \\
\text { pentosaceus }\end{array}$ & AMol-3 & T0 (80) & n.a. & 99 (KP119818.1) & $99.79\left(\mathrm{DSM} 20336^{\mathrm{T}}\right)$ & 1442 & KU240504 & $198(14.3)$ \\
\hline
\end{tabular}

The results refer to mean values for two olive crop seasons

Abbreviations: T100 irrigation supplied $100 \%$ of the ETc, T50 irrigation supplied $50 \%$ of the ETc, T0 rainfed trial, n.a. not amplified

${ }^{a}$ Results obtained by multiplex PCR analysis of the recA gene with species-specific primers for Lactobacillus pentosus, Lactobacillus. plantarum, and Lactobacillus paraplantarum (Torriani et al. 2001)

${ }^{\mathrm{b}}$ Results obtained by the $16 \mathrm{~S}$ rRNA sequence search 


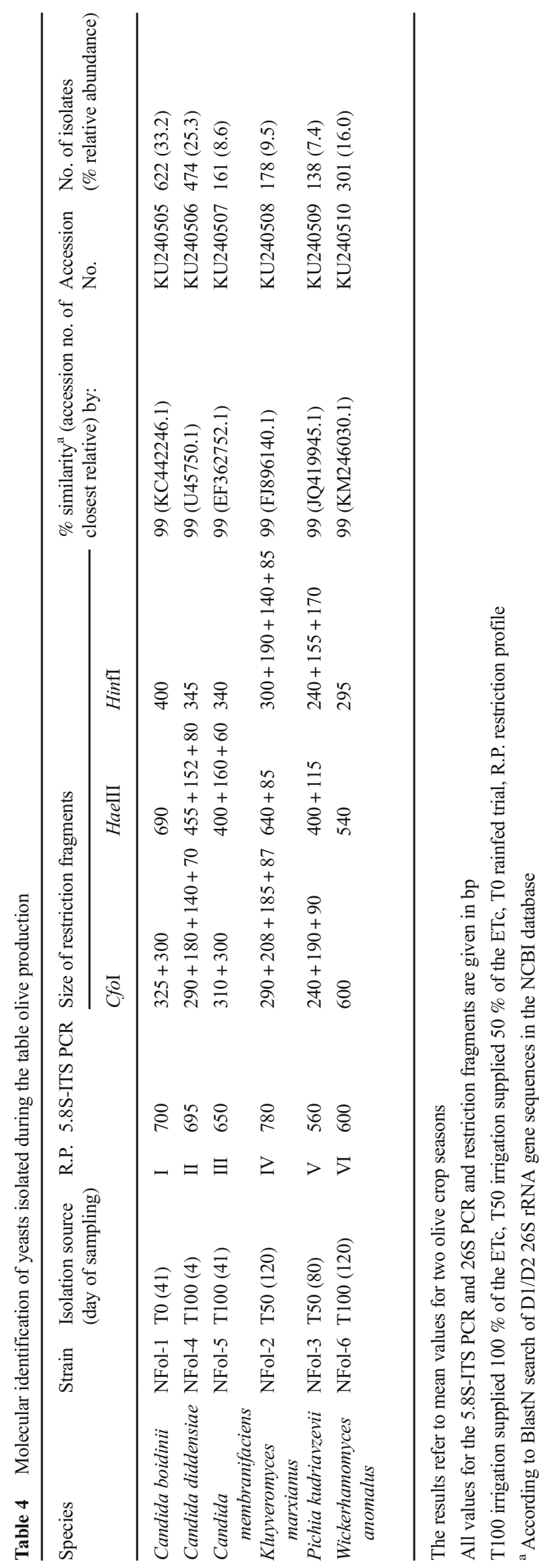


data processing and graphical construction were achieved by using STATISTICA software version 10 (StatSoft Inc., Tulsa, OK, USA) and XLSTAT software version 7.5.2 (Addinsoft, New York, USA) for Excel.

\section{Results}

\section{Carpological, physico-chemical, and microbiological analyses}

Data from the measurements of equatorial diameter, weight, and pit of drupes as well the flesh:pit ratio are reported in Table 1. Experimental treatments mainly affected the equatorial diameter, weight, and flesh:pit ratio, which resulted higher than those registered for the control. Furthermore, no significant differences were found between trials T100 and T50.

The physico-chemical and microbiological characteristics of brine samples collected during the olive manufacturing are reported in Table 2. The $\mathrm{pH}$ ranged between 7.1 (day 0 ) and 3.9 (day 220) for all trials. In particular, trials T100 and T50 showed the highest decrease of $\mathrm{pH}$ within the first 41 days of fermentation; from day 160 onwards, no significant differences among trials were registered.

The microbial groups most often represented on untreated olives were yeasts and total mesophilic bacteria [about 4.0 Log colony-forming units (CFU)/g on average], while LAB were almost two orders of magnitude lower. Members of the Enterobacteriaceae family reached highest levels of 1 Log $\mathrm{CFU} / \mathrm{g}$. Staphylococci and pseudomonads were found at undetectable levels.
During the fermentation, yeasts reached counts higher than LAB throughout the process and in all trials.

The presence of LAB observed in trial T0 was more limited than that registered for the other two trials during the entire period of monitoring. In particular, the levels of LAB were mainly estimated in trials T100 and T50, and they showed the highest concentrations at the end of the process, between days 160 (about $3.5 \mathrm{Log} \mathrm{CFU} / \mathrm{mL}$ ) and 200 (about 6.2 Log CFU/mL).

The Enterobacteriaceae population was detectable until day 24 of the process in all trials, and the highest concentration was estimated for trial T0. Staphylococci and Pseudomonas spp. populations reached the highest concentrations (between 4.6 and $5.5 \mathrm{Log} \mathrm{CFU} / \mathrm{mL}$ ) at day 41 in all trials. Both microbial groups were detected until day 80 for trials T100 and T50 and disappeared from trial T0 after 160 days.

\section{Identification and distribution of $\mathrm{LAB}$ and yeasts}

A total of 2111 colonies were collected from the highest plated dilutions of cell suspensions. The cultures showing a rod shape morphology of the cells typical of lactobacilli were better investigated. A total of 1385 isolates were considered presumptive LAB, as being Gram-positive and catalase-negative. All these cultures were able to grow at $15{ }^{\circ} \mathrm{C}$, unable to develop at $45{ }^{\circ} \mathrm{C}$, and were facultatively homofermentative because of their inability to generate $\mathrm{CO}_{2}$ from glucose and their growth in the presence of pentose carbohydrates. Owing to the high number of isolates, about $40 \%$ of the cultures (selected to be representative of the isolation source, colony
Fig. 1 Evaluation of sensory attributes of table olives at 220 days of fermentation

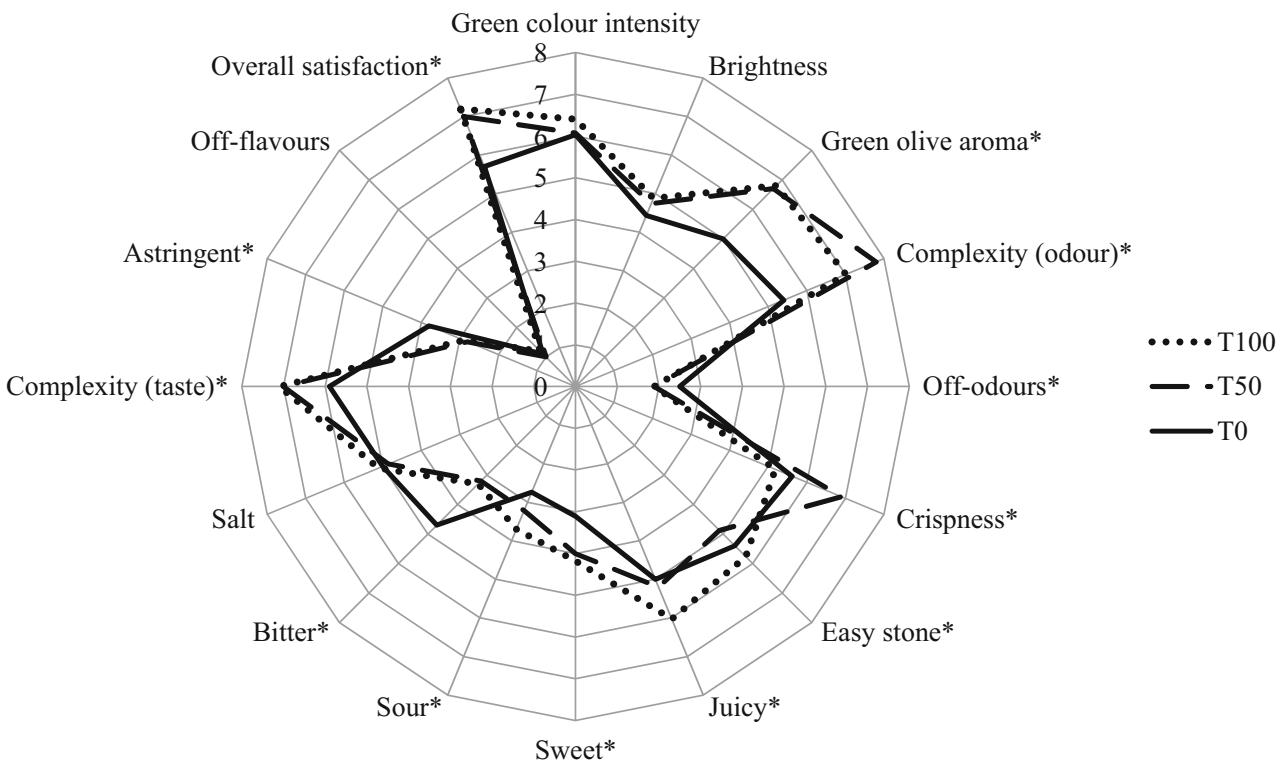

Results indicate mean values of three replicate per each trials (carried out in triplicate for two olive crop seasons) Abbreviations: T100, irrigation supplied $100 \%$ of ETc; T50, irrigation supplied $50 \%$ of ETc; T0, rainfed trial $*$ indicate significant differences among experimental trials for the same sample $(p<0.05)$ 
morphology, experimental trial, and year of production) were grouped on the basis of the RAPD-PCR profiles and subsequently identified at the species level by multiplex PCR analysis. This analysis revealed the presence of L. pentosus and L. plantarum (Table 3). Furthermore, the identification process continued by using $16 \mathrm{~S}$ rRNA gene sequencing, which confirmed the presence of $L$. pentosus and $L$. plantarum, and revealed the presence of Lactobacillus coryniformis and Pediococcus pentosaceus among the bacteria resulted negative to the multiplex PCR specific for the L. plantarum group. The species $L$. plantarum and $L$. pentosus were mainly found during the fermentation of the trials T100 and T50. Lactobacillus coryniformis and P. pentosaceus were isolated only in T50 (day 120) and T0 (day 80).

The yeast population that characterized the olive manufacturing process was also subjected to molecular investigation. A total of 1874 yeast colonies were collected from DRBC agar. Based on colony and cell morphology, 671 isolates were subjected to molecular identification. After restriction analysis of the 5.8SITS region, the isolates were clustered into six groups (Table 4).
Sequencing of the D1/D2 domain of the 26S rRNA gene identified six species: Candida boidinii, Candida diddensiae, Candida membranifaciens, Kluyveromyces marxianus, Pichia kudriavzevii, and Wickerhamomyces anomalus.

With regards to the distribution of yeast species, C. diddensiae, C. membranifaciens, and W. anomalus were isolated mainly from the olives of the trials T100 and T50; the latter samples showed the highest diversity of yeast because $P$. kudriavzevii and K. marxianus were also found. Trial T0 showed very limited yeast diversity, since only $C$. boidinii was identified.

\section{Sensory evaluation}

The results of the sensory analysis are reported in Fig. 1. Significant differences among the three trials were registered for green olive aroma, acid, bitter, firmness, crunchiness, and overall descriptors. In particular, both irrigated trials T100 and T50 showed the highest scores for green olive aroma, odor and flavor complexity, crispness, sweet, and overall

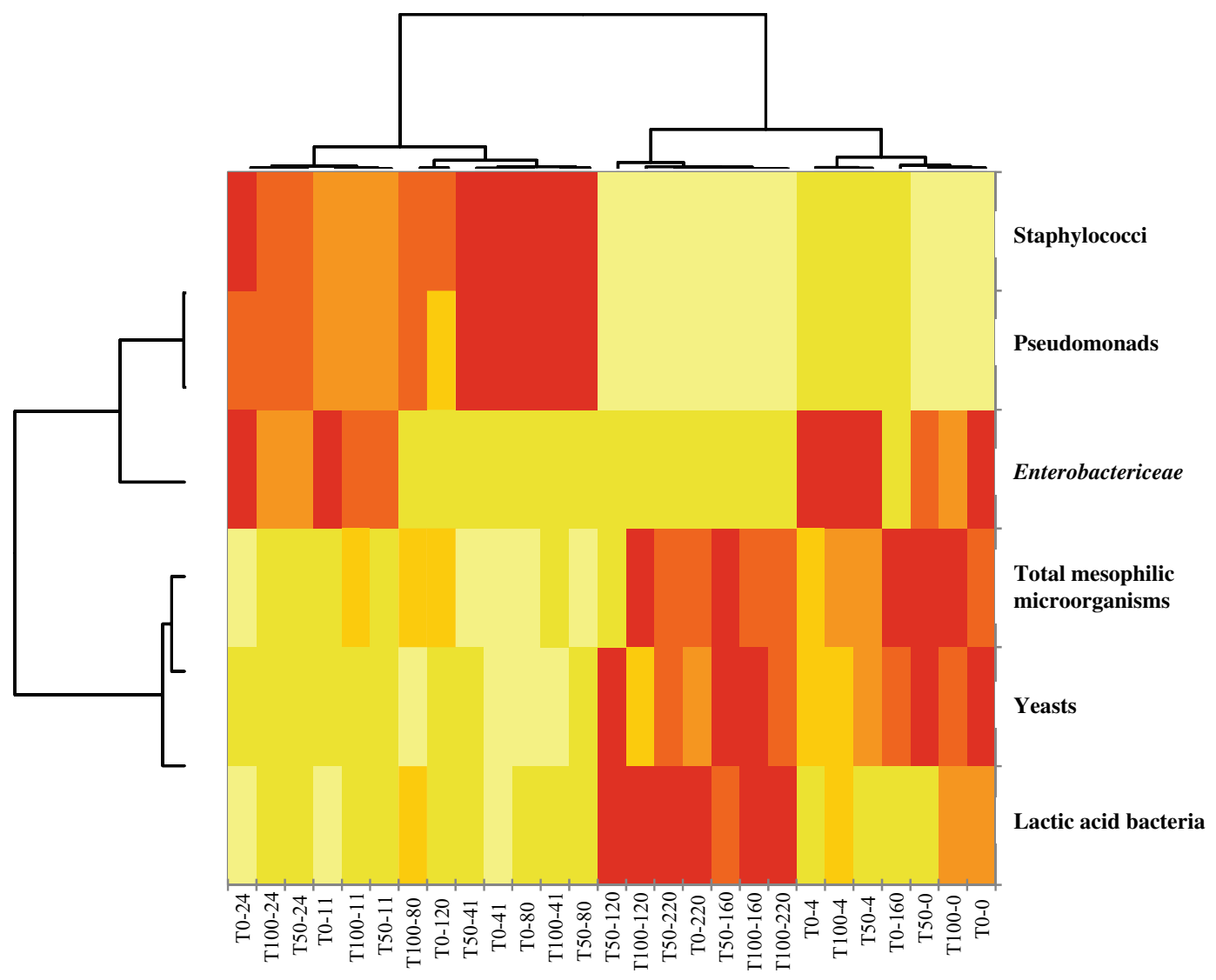

Results indicate mean values of three replicate per each trials (carried out in triplicate for two olive crop seasons) Abbreviations: T100, irrigation supplied $100 \%$ of ETc; T50, irrigation supplied $50 \%$ of ETc; T0, rainfed trial The values for microbial groups are depicted by color intensity from yellow (lowest concentration) to red (highest concentration). Clusters based on the distance of the samples along the $\mathrm{X}$-axis and the microbial groups along the $\mathrm{Y}$-axis are indicated in the upper and left sections of the figure, respectively. Codes (T0, T50 and T100) correspond to experimental trials. The numbers associated to each code correspond to day of fermentation per each experimental trials

Fig. 2 Microbial population distribution among samples. The double hierarchical dendrogram is based on values of microbiological counts. The heat map plot depicts the relative percentage of each microbial group (variables clustering on the Y-axis) within each sample (X-axis clustering) 
satisfaction. In contrast, the highest values of acid, bitter, firmness, and crunchiness were found for the olives obtained from the rainfed trial.

\section{Statistical and explorative multivariate analysis}

The statistical analysis was performed mainly to show significant differences among data collected during the two olive crop seasons. The results obtained from a GLM based on the ANOVA model showed no significant effect between crop seasons and the dependent variables associated to carpological, physico-chemical, and microbiological data.

The HMCA (Fig. 2) clearly separated LAB, yeasts, and total mesophilic bacteria from members of the Enterobacteriaceae family, pseudomonads, and staphylococci as an effect of the irrigation. At the same time, the HMCA grouped samples in two mega-clusters characterized from different relative abundances of microbial populations. One mega-cluster (mainly represented by trials T100 and T50) showed the highest concentration of LAB (between days 120 and 220) and Enterobacteriaceae (between days 0 and 4). In contrast, the second mega-cluster (mainly represented by trial T0) was characterized by the highest relative abundances of pseudomonads and staphylococci.

In order to better analyze the differences among trials, the results obtained by monitoring microbial counts, $\mathrm{pH}$ values, and carpological characteristics of drupes were also subjected to PCAn. This type of analysis condensed the information from 25 variables into a restricted number of factors. The score and loading plots are visualized in Fig. 3a, b, respectively. Trial T0 resulted in being significantly separated from the other trials along factor 1 that explained $46.27 \%$ of the total variance. Trials T50 and T100 were also represented onto different quadrants of the score plot but only along factor 2 that explained $28.04 \%$ of the total variance. The 25 variables were expressed as a linear combination of two factors in a loading plot (Fig. 3a) that explained $74.31 \%$ of the total variance. In detail, the loading plot showed that factor 1 has been more closely related to the variables MRS $(0.96)$, BP $(-0.92)$, and PAB (-0.94). Furthermore, factor 2 was mainly correlated to the variables FW (0.84), DRBC (0.82), MaxVRBGA $(-0.61)$, and MinPCA $(-0.78)$.

\section{Discussion}

The aim of the present study was to evaluate the effect of different amounts of water supplied by irrigation on the quality of green table olives belonging to cv. Nocellara del Belice. According to the scientific literature, several studies evaluated the physiological response and performance of olive trees grown under RDI (d'Andria et al. 2009), as well as the overall (a)

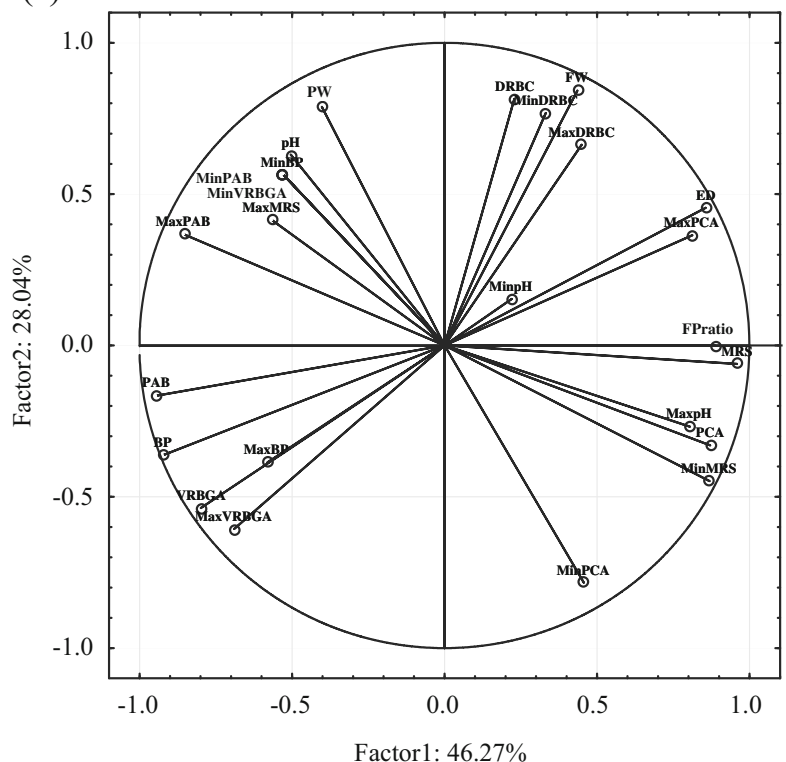

(b)

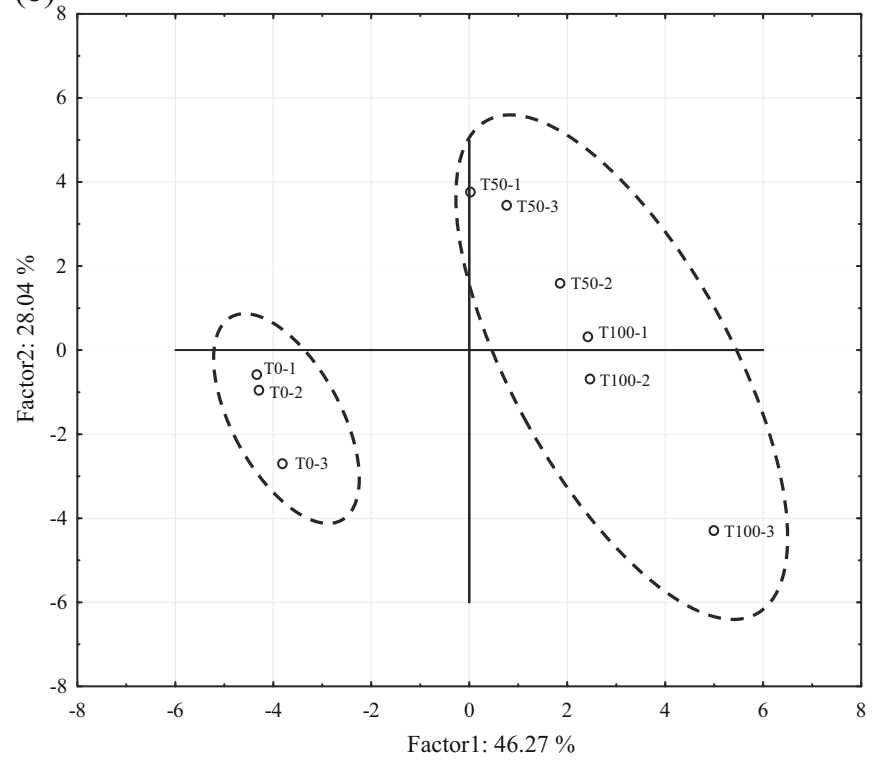

Results indicate mean values of three replicate per each trials (carried out in triplicate for two olive crop seasons)

Abbreviations: MRS,Man-Rogosa-Sharpe agar for mesophilic rod LAB; DRBC, dichloran rose bengal chloramphenicol agar for total yeasts and filamentous fungi; VRBGA, violet red bile glucose agar for Enterobacteriaceae; PAB, pseudomonas agar base for pseudomonads. 'Max'and 'Min' correspond to the maximum and minimum values of $\mathrm{pH}$ and microbial populations detected on the corresponding medium used for counts; ED, equatiorial diameter of fruit; PW, pit weight, FP, flesh:pit ratio

The codes (T0, T50, and T100) correspond to the experimental trials. The numbers associated to each code correspond to replicates per experimental trial Ann Microbiol

Fig. 3 Principal component analysis (PCA) analysis based on the values of carpological, physico-chemical, and microbiological data (a: loading plot; b: score plot) 
development and composition of drupes (Chaves et al. 2010). In our study, within the carpological results, the irrigation mainly affected the equatorial diameter and flesh:pit ratio of fruits, which resulted significantly higher in the trials subjected to irrigation. Interestingly, drupes of trial T50 showed values of carpological measurements similar to that registered for trial T100. Cano-Lamadrid et al. (2015) also observed the highest equatorial diameter in fruits submitted to irrigation during stone hardening. Similar results were reported by Proietti and Antognozzi (1996) and Aponte et al. (2012) for olives harvested from irrigated trees. Regarding the influence of the irrigation regimes on the microbiology of the process of table olive transformation, only the work of Aponte et al. (2012) is available in the literature. However, in that work, table olives were produced according to the Sevillian-style, which includes the addition of a starter culture. No data have been published for the Greek-style table olive production system that involves a spontaneous fermentation determined by the indigenous microbiota.

In accordance to our results on $\mathrm{pH}$ changes, Marsilio et al. (2006) reported a greater decrease of $\mathrm{pH}$ in fermenting brines of olives collected from irrigated trees than those from the rainfed trial. The $\mathrm{pH}$ values are of paramount importance for the growth of microbial populations, and the $\mathrm{pH}$ significantly affects the development of spoilage and potentially pathogenic bacteria. In our study, the concentrations of spoilage microorganisms were in agreement with those estimated by Aponte et al. (2012). Enterobacteriaceae, pseudomonads, and staphylococci were more abundant in the trial that was not irrigated and the highest concentrations were found at the beginning of the manufacturing process. The high counts of xerophilic groups such as staphylococci could be related to the supply of the deficit irrigation and the consequent changes in the chemical composition in the leaves (Chehab et al. 2009) and drupes Aponte et al. (2012).

In our study, although yeast concentrations were mainly higher than LAB during brine fermentation, the trials $\mathrm{T} 100$ and T50 were characterized by an optimal dynamics of concentration of these microbial populations (Aponte et al. 2012; Martorana et al. 2015); thus, an appropriate decrease of $\mathrm{pH}$ was registered throughout olive manufacturing. Bleve et al. (2015) demonstrated that the spontaneous fermentations of Conservolea and Kalamàta black olives were driven by yeasts during the first half of the process and, after that, by yeasts and $\mathrm{LAB}$ until the end of the process.

In our study, fermented table olives from the trials T100 and T50 showed, overall, the highest score of sensory overall satisfaction from assessors. Cano-Lamadrid et al. (2015) also observed positive effects on the quality and consumers' satisfaction degree of table olives from moderate irrigation. In contrast, Aponte et al. (2012) did not show significant differences among samples coming from irrigated and not irrigated groves, a result imputable to the action of the LAB strains added as starter culture.
The explorative multivariate analysis, widely applied in table olive production (Bautista-Gallego et al. 2011; Rodríguez-Gómez et al. 2012a, b, 2013; Martorana et al. 2015,2016 ), clearly showed a significant effect of the irrigation on the final products.

\section{Conclusions}

In conclusion, our work provided an overview on the microbial ecology of olives collected from trees subjected to two regulated deficit irrigation (RDI) regimes and a rainfed treatment. In comparison to the rainfed trial, the use of irrigation favored carpological features of drupes and the development of lactic acid bacteria (LAB) during the manufacturing process, in particular $L$. pentosus and L. plantarum. All aspects of the composition of the irrigated olives were in agreement with those reported for the commercial standards, and spoilage microorganisms and undesired sensory aspects were not affected by RDI treatments. In addition, fermented olives from trial T50 were characterized by scores of sensory attributes similar to that of trial T100, as well as with the highest sensory overall satisfaction degree.

Interestingly, the statistical analysis showed that the effect of irrigation was independent from the seasonal variability.

These results showed that a reduced irrigation allows the production of table olives with characteristics highly similar to those obtained with the full irrigation. Thus, this study showed a strategy for an efficient water saving during olive tree cultivation without negative effects on the final quality of the table olives produced with the cv. "Nocellara del Belice".

Although this research was undertaken in triplicate and during two consecutive season crops, further investigations with other cultivars and with different RDI regimes are being prepared to extend the knowledge of the effect of irrigation on the quality of the resulting fermented products.

Acknowledgments This work was financially supported by PON Ricerca e Competitività 2007-2013 Progetto "Di.Me.Sa."Valorizzazione di prodotti tipici della Dieta Mediterranea e loro impiego a fini salutistici e nutraceutici. Codes of project: PON02_00667 and PON02_00451_3361785.

\section{References}

Allen RG, Pereira LS, Raes D, Smith M (1998) Crop evapotranspiration (guidelines for computing crop water requirements). FAO irrigation and drainage paper 56. Food and Agriculture Organization of the United Nations (FAO), Rome

Aponte M, Blaiotta G, La Croce F, Mazzaglia A, Farina V, Settanni L, Moschetti G (2012) Use of selected autochthonous lactic acid bacteria for Spanish-style table olive fermentation. Food Microbiol 30: $8-16$ 
Arroyo-López FN, Querol A, Bautista-Gallego J, Garrido-Fernández A (2008) Role of yeasts in table olive production. Int J Food Microbiol 128:189-196

Bautista-Gallego J, Arroyo-López FN, Romero Gil V, Rodríguez Gómez F, García García P, Garrido Fernández A (2011) Chloride salt mixtures affect Gordal cv. green Spanish-style table olive fermentation. Food Microbiol 28:1316-1325

Blana VA, Grounta A, Tassou CC, Nychas GJE, Panagou EZ (2014) Inoculated fermentation of green olives with potential probiotic Lactobacillus pentosus and Lactobacillus plantarum starter cultures isolated from industrially fermented olives. Food Microbiol 38:208-218

Bleve G, Tufariello M, Durante M, Grieco F, Ramires FA, Mita G, Tasioula-Margari M, Logrieco AF (2015) Physico-chemical characterization of natural fermentation process of Conservolea and Kalamàta table olives and developement of a protocol for the preselection of fermentation starters. Food Microbiol 46:368-382

Cano-Lamadrid M, Girón IF, Pleite R, Burló F, Corell M, Moriana A, Carbonell-Barrachina AA (2015) Quality attributes of table olives as affected by regulated deficit irrigation. LWT Food Sci Technol 62:19-26

Caruso T, Di Marco L (1982) Indagine sull'areale di coltivazione dell'Olivo "Nocellara del Belice" nei comuni di Partanna, Castelvetrano, Campobello di Mazara. Cooperativa centro stampa siciliana, Palermo

Chaves MM, Zarrouk O, Francisco R, Costa JM, Santos T, Regalado AP, Rodrigues ML, Lopes CM (2010) Grapevine under deficit irrigation: hints from physiological and molecular data. Ann Bot 105: 661-676

Chehab H, Mechri B, Mariem FB, Hammami M, Ben Elhadj S, Braham M (2009) Effect of different irrigation regimes on carbohydrate partitioning in leaves and wood of two table olive cultivars (Olea europaea L. cv. Meski and Picholine). Agric Water Manag 96:293-298

d'Andria R, Lavini A, Morelli G, Sebastiani L, Tognetti R (2009) Physiological and productive responses of Olea europaea L. cultivars Frantoio and Leccino to a regulated deficit irrigation regime. Plant Biosyst 143:222-231

Dillon WR, Goldstein M (1984) Multivariate analysis: methods and applications. Wiley, New York

Doorenbos J, Pruitt WO (1977) Crop water requirements. FAO irrigation and drainage paper 24. Food and Agriculture Organization of the United Nations (FAO), Rome

Esteve-Zarzoso B, Belloch C, Uruburu F, Querol A (1999) Identification of yeasts by RFLP analysis of the 5.8S rRNA gene and the two ribosomal internal transcribed spacers. Int J Syst Evol Microbiol 49:329-337

Fereres E, Castel JR (1981) Drip irrigation management. Division of Agricultural Sciences, University of California. Leaflet 21259

Fernández-Díez MJ, de Castro R, Garrido-Fernández A, González F, González-Pellissó F, Nosti M, Heredia A, Mínguez MI, Rejano L, Durán Quintana MC, Sánchez F, García P, de Castro A (1985) Biotecnología de la Aceituna de Mesa. CSIC, Madrid

Francesca N, Romano R, Sannino C, Le Grottaglie L, Settanni L, Moschetti G (2014) Evolution of microbiological and chemical parameters during red wine making with extended post-fermentation maceration. Int J Food Microbiol 171:84-93

Gaglio R, Francesca N, Di Gerlando R, Cruciata M, Guarcello R, Portolano B, Moschetti G, Settanni L (2014) Identification, typing and investigation of the dairy characteristics of lactic acid bacteria isolated from "Vastedda della valle del Belìce" cheeses. Dairy Sci Technol 94:157-180

García P, Romero C, Brenes M (2014) Influence of olive tree irrigation and the preservation system on the fruit characteristics of Hojiblanca black ripe olives. LWT Food Sci Technol 55:403-407

Garrido A, García P, Brenes M (1995) Olive fermentations. In: Rehm HJ, Reed G (eds) Biotechnology. VCH, Weinheim, pp 593-627
Garrido Fernández A, Fernández Díez MJ, Adams MR (1997) Table olives: production and processing. Chapman \& Hall, London

Goldhamer DA (1999) Regulated deficit irrigation for California canning olives. Acta Hortic 474:369-372

Gómez-Rico A, Salvador MD, La Greca M, Fregapane G (2006) Phenolic and volatile compounds of extra virgin olive oil (Olea europaea L. cv. Cornicabra) with regard to fruit ripening and irrigation management. J Agric Food Chem 54:7130-7136

Gómez-Rico A, Salvador MD, Moriana A, Pérez D, Olmedilla N, Ribas F, Fregapane G (2007) Influence of different irrigation strategies in a traditional Cornicabra cv. olive orchard on virgin olive oil composition and quality. Food Chem 100:568-578

Heperkan D (2013) Microbiota of table olive fermentations and criteria of selection for their use as starters. Front Microbiol 4:143

Iniesta F, Testi L, Orgaz F, Villalobos FJ (2009) The effects of regulated and continuous deficit irrigation on the water use, growth and yield of olive trees. Eur J Agron 30:258-265

Jolliffe IT (1986) Principal component analysis. Springer, New York

Lavee S, Nashef M, Wodner M, Harshemesh H (1990) The effect of complementary irrigation added to old olive trees (Olea europaea L.) cv. Souri on fruit characteristics, yield and oil production. Adv Hortic Sci 4:135-138

Marsilio V, d'Andria R, Lanza B, Russi F, Iannucci E, Lavini A, Morelli $G$ (2006) Effect of irrigation and lactic acid bacteria inoculants on the phenolic fraction, fermentation and sensory characteristics of olive (Olea europaea L. cv. Ascolana tenera) fruits. J Sci Food Agric 86:1005-1013

Martorana A, Alfonzo A, Settanni L, Corona O, La Croce F, Caruso T, Moschetti G, Francesca N (2015) An innovative method to produce green table olives based on "pied de cuve" technology. Food Microbiol 50:126-140

Martorana A, Alfonzo A, Settanni L, Corona O, La Croce F, Caruso T, Moschetti G, Francesca N (2016) Effect of the mechanical harvest of drupes on the quality characteristics of green fermented table olives. J Sci Food Agric 96:2004-2017

Mazzei P, Francesca N, Moschetti G, Piccolo A (2010) NMR spectroscopy evaluation of direct relationship between soils and molecular composition of red wines from Aglianico grapes. Anal Chim Acta 673:167-172

Michelakis N (1990) Yield response of table and oil olive varieties to different water use levels under drip irrigation. Acta Hortic 286: 271-274

Pastor M, Humanes J, Vega V, Castro J (1998) Diseño y manejo de plantaciones de olivar. Monografías 22/98. Junta de Andalucía, pp 204-206

Patumi M, d'Andria R, Marsilio V, Fontanazza G, Morelli G, Lanza B (2002) Olive and olive oil quality after intensive monocone olive growing (Olea europaea L., cv. Kalamata) in different irrigation regimes. Food Chem 77:27-34

Proietti P, Antognozzi E (1996) Effect of irrigation on fruit quality of table olives (Olea europaea) cultivar 'Ascolana tenera'. New Zeal J Crop Hort 24:175-181

Rodríguez-Gómez F, Bautista-Gallego J, Romero-Gil V, Arroyo-López FN, Garrido-Fernández A, García-García P (2012a) Effects of salt mixtures on Spanish green table olive fermentation performance. LWT Food Sci Technol 46:56-63

Rodríguez-Gómez F, Romero-Gil V, Bautista-Gallego J, GarridoFernández A (2012b) Multivariate analysis to discriminate yeast strains with technological applications in table olive processing. World J Microbiol Biotechnol 28:1761-1770

Rodríguez-Gómez F, Bautista-Gallego J, Arroyo-López FN, Romero-Gil V, Jiménez-Díaz R, Garrido-Fernández A, García-García P (2013) Table olive fermentation with multifunctional Lactobacillus pentosus strains. Food Control 34:96-105

Servili M, Esposto S, Lodolini E, Selvaggini R, Taticchi A, Urbani S, Montedoro G, Serravalle M, Gucci R (2007) Irrigation effects on 
quality, phenolic composition, and selected volatiles of virgin olive oils cv. Leccino. J Agric Food Chem 55:6609-6618

Servizio Informativo Agrometeorologico Siciliano (SIAS) Home page at: http://www.sias.regione.sicilia.it

Torriani S, Felis GE, Dellaglio F (2001) Differentiation of Lactobacillus plantarum, $L$. pentosus, and $L$. paraplantarum by recA gene sequence analysis and multiplex PCR assay with recA gene-derived primers. Appl Environ Microbiol 67:3450-3454

Tovar MJ, Romero MP, Girona J, Motilva MJ (2002) L-Phenylalanine ammonia-lyase activity and concentration of phenolics in developing olive (Olea europaea L cv Arbequina) fruit grown under different irrigation regimes. J Sci Food Agric 82:892-898

UNI 10957 (2003) Sensory analysis: method for establishing a sensory profile in foodstuffs and beverages. Standards Library, HIS Engineering 360

Vossen P (2007) Pruning olive trees: how to minimize alternate bearing and improve production. Newsl Olive Oil Prod Eval 2(3):1-4

Weisburg WG, Barns SM, Pelletier DA, Lane DJ (1991) 16S ribosomal DNA amplification for phylogenetic study. J Bacteriol 173:697-703 